\title{
Relationship between genotype for the cytochrome P450 CYP2D6 and susceptibility to ankylosing spondylitis and rheumatoid arthritis
}

\author{
C Beyeler, M Armstrong, H A Bird, J R Idle, A K Daly
}

\begin{abstract}
Objectives-To determine whether particular genotypes for the cytochrome P450 enzyme CYP2D6, a polymorphic enzyme, are associated with susceptibility to ankylosing spondylitis (AS) and rheumatoid arthritis (RA), or linked with any specific clinical or familial features of the two conditions.

Methods-CYP2D6 genotypes were determined in 54 patients with AS, 53 patients with RA, and 662 healthy controls. Leucocyte DNA was analysed for the presence of mutations by restriction fragment length polymorphism analysis with the restriction enzyme $\mathrm{Xbal}$ and by two separate polymerase chain reaction assays.

Results-On the basis of odds ratio (OR), individuals with two inactive CYP2D6 alleles were more susceptible to AS than controls (OR $2 \cdot 71,95 \%$ confidence interval (CI) 1.04 to 7.08 ), with a stronger effect for the CYP2D6B allele (OR 4.11, 95\% CI 1.54 to $11 \cdot 0)$. No significant differences in the distribution of overall genotypes and allele frequencies were observed between RA and controls. No significant relationships were found between the skeletal, extraskeletal or familial features of AS or RA (iritis, psoriasis, inflammatory enteropathy and rheumatoid nodules, keratoconjunctivitis sicca, pleuritis, rheumatoid and antinuclear factors) and the overall genotype.
\end{abstract}

Conclusions-Our findings suggest a modest association between homozygosity for inactive CYP2D6 alleles, particularly CYP2D6B alleles, and susceptibility to AS. However, our results fail to demonstrate a genetic link between CYP2D6 genotype and RA.

(Ann Rheum Dis 1996; 55: 66-68)

Genetic factors have an important role in determining susceptibility to rheumatic diseases and adverse drug reactions. Cytochrome P450 enzymes are responsible for the majority of oxidative (phase I) drug metabolism. ${ }^{1}$ The cytochrome $\mathbf{P 4 5 0}$ enzyme CYP2D6 is polymorphic with $5-10 \%$ of Europeans lacking this activity (described as poor metabolisers) compared with extensive metabolisers. $^{2}$ The genetic basis of this deficiency is now well understood, and genotyping methods allow the identification of more than $95 \%$ of poor metabolisers. ${ }^{3}$ Polymorphisms in the gene encoding this enzyme have been linked with susceptibility to various diseases including certain cancers ${ }^{4}$ and systemic lupus erythematosus, ${ }^{5}$ but not scleroderma. ${ }^{6}$ They are also linked to adverse drug reactions of at least 30 different therapeutically important drugs including antiarrhythmics, neuroleptics, antihypertensives and analgesics including codeine and dextropropoxyphene, both used widely in rheumatology. ${ }^{2}$ Ankylosing spondylitis (AS) is strongly linked genetically with the HLA-B27 antigen. ${ }^{7}$ Rheumatoid arthritis (RA) is associated with several subtypes of HLA-DR4, which share a similar sequence of the DR $\beta$ chain. ${ }^{8}$ However, in both rheumatic diseases there are likely to be additional predisposing genes besides HLA-B27 and -DR4 subtypes, which may or may not be HLA linked. Such additional genetic factors and gender may influence disease expression and severity.

In view of the reported association of CYP2D6 genotype with the other chronic inflammatory disease, systemic lupus erythematosus, it seemed appropriate to study the genotype in AS and RA to determine whether this might form a susceptibility marker when compared with a control population, and whether it is linked with any specific clinical features of the conditions.

Patients and methods

Ethics commitee approval was obtained from the appropriate ethics committees. All patients and controls gave consent to participate in the study.

Fifty four patients with ankylosing spondylitis (AS) according to the modified New York criteria ${ }^{9}$ were recruited from the rheumatology outpatients department at the General Infirmary at Leeds, UK. There were 47 men, and seven women, mean age 47 (SD 10.8) years and mean duration of AS $20(10.9)$ years. From the same department, 53 patients with rheumatoid arthritis (RA) fulfilling the modified American Rheumatism Association criteria ${ }^{10}$ were studied: 42 were women and 11 were men, mean age $59(12 \cdot 1)$ years and mean duration of RA $11(10 \cdot 7)$ years. All had RA for at least six months and disease activity considered sufficient to warrant the use of a conventional disease modifying antirheumatic drug. The control group comprised 662 healthy volunteers recruited from the staff of a 
British pharmaceutical company and the staff and students of the University of Newcastleupon-Tyne, UK: 285 were women, 377 were men, and the mean age was $35 \cdot 2(9 \cdot 9)$ years.

For all patients one physician (CB) completed a questionnaire about the skeletal and extraskeletal features and age of onset of the rheumatic diseases, and about the family history of AS, psoriasis, inflammatory enteropathy, and RA.

CYP2D6 genotypes were determined by assay of leucocyte DNA extracted from EDTA blood samples transported from Leeds to Newcastle. Samples were analysed for the presence of mutations in the CYP2D6 gene cluster, by restriction fragment length polymorphism analysis with $\mathrm{Xbal}$ and a CYP2D6 cDNA probe (CYP2D6D, CYP2D6E alleles) and polymerase chain reactions specific for CYP2D6A and CYP2D6B alleles, respectively. ${ }^{3}$ It has been demonstrated that a combination of these analyses detected about $95 \%$ of phenotypic poor metaboliser subjects as genotypic poor metabolisers. The four different mutant alleles (CYP2D6A, CYP2D6B, CYP2D6D, CYP2D6E) analysed are associated with lack of CYP2D6 activity, and an individual homozygous for one or heterozygous for two of these alleles shows a poor metaboliser metabolic phenotype.

Table 1 Risk of $A S$ and $R A$ development in relation to genotype

\begin{tabular}{|c|c|c|}
\hline Genotype & $\begin{array}{l}\text { Frequency } \\
\text { (No (\%) }[95 \% \text { CI]) }\end{array}$ & $\begin{array}{l}\text { Odds ratio [95\% CI] } \\
\text { v controls }\end{array}$ \\
\hline \multicolumn{3}{|l|}{ Wild-type†/wild-type } \\
\hline $\begin{array}{l}\text { AS } \\
\text { RA } \\
\text { Controls }\end{array}$ & $\begin{array}{r}26(48 \cdot 2)[35 \text { to } 61] \\
35(66 \cdot 0)[53 \text { to } 79] \\
364(55 \cdot 0)[51 \text { to } 59]\end{array}$ & $\begin{array}{l}1 \\
1\end{array}$ \\
\hline \multicolumn{3}{|l|}{ Wild-type/mutant } \\
\hline $\begin{array}{l}\text { AS } \\
\text { RA } \\
\text { Controls }\end{array}$ & $\begin{array}{r}22(40 \cdot 7)[28 \text { to } 54] \\
14(26 \cdot 4)[15 \text { to } 38] \\
267(40 \cdot 3)[37 \text { to } 44]\end{array}$ & $\begin{array}{l}0.62[0.34 \text { to } 1.12] \\
0.55[0.29 \text { to } 1.03]\end{array}$ \\
\hline \multicolumn{3}{|l|}{ Mutant/mutant } \\
\hline $\begin{array}{l}\text { AS } \\
\text { RA } \\
\text { Controls }\end{array}$ & $\begin{array}{l}6(11 \cdot 2)[3 \text { to } 19] \\
4(7 \cdot 6)[0 \text { to } 15] \\
31(4 \cdot 7)[3 \text { to } 6]\end{array}$ & $\begin{array}{l}2.71[1.04 \text { to } 7.08] \\
1.34[0.45 \text { to } 4.02]\end{array}$ \\
\hline
\end{tabular}

†Not positive for CYP2D6A, CYP2D6B, CYP2D6D, CYP2D6E alleles.

¥Positive for CYP2D6A, CYP2D6B, CYP2D6D or CYP2D6E allele.

Table 2 Distribution of alleles in ankylosing spondylitis (AS), rheumatoid arthritis (RA) and healthy controls

\begin{tabular}{llcc}
\hline Allele & $A S(n=108)$ & $R A(n=106)$ & Controls $(n=1324)$ \\
\hline Wild-type & $74(68 \cdot 5)[60$ to 77$]$ & $84(79 \cdot 3)[72$ to 87$]$ & $995(75 \cdot 2)[73$ to 77$]$ \\
CYP2D6A & $3(2 \cdot 8)[0$ to 6$]$ & $1(0 \cdot 9)[0$ to 3$]$ & $19(1 \cdot 4)[1$ to 2$]$ \\
CYP2D6B & $29(26 \cdot 9)[18$ to 35$]$ & $20(18 \cdot 9)[11$ to 26$]$ & $257(19 \cdot 4)[17$ to 22$]$ \\
CYP2D6D & $1(0 \cdot 9)[0$ to 3$]$ & $1(0 \cdot 9)[0$ to 3$]$ & $51(3.9)[3$ to 5$]$ \\
CYP2D6E & $1(0.9)[0$ to 3$]$ & 0 & $2(0 \cdot 1)[0$ to $0 \cdot 4]$ \\
\hline
\end{tabular}

Values are number (\%) $[95 \% \mathrm{CI}]$.

Table 3 Risk for possession of CYP2D6B allele in $A S$ and $R A$

\begin{tabular}{|c|c|c|}
\hline Alleles & (No (\%) $[95 \%$ CI] $)$ & $\begin{array}{l}\text { Odds ratio }[95 \% \text { CI] } \\
\text { v controls }\end{array}$ \\
\hline $\begin{array}{l}\text { No B allele } \\
\text { AS } \\
\text { RA } \\
\text { Controls }\end{array}$ & $\begin{array}{r}31(57 \cdot 4)[44 \text { to } 71] \\
36(67 \cdot 9)[55 \text { to } 80] \\
425(64 \cdot 2)[62 \text { to } 66]\end{array}$ & $\begin{array}{l}1 \\
1\end{array}$ \\
\hline $\begin{array}{l}\text { One B allele } \\
\text { AS } \\
\text { RA } \\
\text { Controls }\end{array}$ & $\begin{array}{r}17(31 \cdot 5)[19 \text { to } 44] \\
14(26 \cdot 4)[16 \text { to } 38] \\
217(32 \cdot 8)[29 \text { to } 36]\end{array}$ & $\begin{array}{l}1.07[0.58 \text { to } 1.98] \\
0.76[0.40 \text { to } 1.44]\end{array}$ \\
\hline $\begin{array}{l}\text { Two B alleles } \\
\text { AS } \\
\text { RA } \\
\text { Controls }\end{array}$ & $\begin{array}{l}6(11 \cdot 1)[3 \text { to } 19] \\
3(5 \cdot 7)[0 \text { to } 12] \\
20(3 \cdot 0)[2 \text { to } 4]\end{array}$ & $\begin{array}{l}4.11[1.54 \text { to } 11.0] \\
1.77[0.50 \text { to } 6.24]\end{array}$ \\
\hline
\end{tabular}

Statistical analyses included $95 \%$ confidence interval (CI) of proportions, $\chi^{2}$ tests for comparison of genetic differences between populations and Student's $t$ test for comparison of age at onset of the disease. Odds ratios (OR) with $95 \%$ CI were calculated using the computer program CIA. ${ }^{11}$ The level of statistical significance was set at $p=0.05$ with two sided analysis.

\section{Results}

Table 1 shows the prevalence of the three separate genotypes in AS, RA, and controls and the odds ratio for development of the two diseases with the homozygous wild-type genotype as baseline. The value of 2.71 calculated for the homozygous mutant genotype and susceptibility to AS is significant on the basis of the $95 \%$ confidence interval. Table 2 shows the prevalence of the different alleles in the three populations studied. There was a tendency for more CYP2D6B alleles in the AS group, and when odds ratios for AS development for the presence of one or two CYP2D6B alleles with no CYP2D6B alleles as baseline were calculated (table 3), a significantly increased risk of AS development (4.11 with $95 \%$ CI 1.54 to 11.0 ) was observed for individuals with two CYP2D6B alleles.

Twenty one of the AS patients described peripheral arthritis $(37 \%), 20$ iritis (37\%), seven psoriasis $(13 \%)$, and one inflammatory enteropathy $(2 \%)$. Ten patients gave a family history of AS $(18 \%)$, seven a family history of psoriasis $(13 \%)$, and one a family history of inflammatory enteropathy (2\%). Twenty five of 29 were genotyped HLA-B27 positive $(86 \%)$. Relationships were sought between all the various features and the three genotype classes. None emerged, though there was a trend suggesting that AS patients with homozygous mutant genotypes may have had an earlier onset of disease $(23(7 \cdot 3)$ years) than those with heterozygous $(25(9 \cdot 8)$ years $)$ and homozygous wild-type genotypes (29 (9.0) years). These findings lend support to a possible relationship between gradation of genetic make up and disease onset of AS.

Twenty six of the RA patients gave a history of rheumatoid nodules (49\%), 23 keratoconjunctivitis sicca $(42 \%)$, one pleuritis $(2 \%)$, and none vasculitis $(0 \%)$. Fourteen patients reported one or more relatives of first or second grade affected by RA $(26 \%)$. At the time of the study, 29 patients had a rheumatoid factor titre greater than $16(55 \%), 15$ were antinuclear factor positive (28\%) and 40 of 47 had radiographic changes typical of RA ( $85 \%)$. No associations were found between all those features and the three genotype classes. In addition, age of onset of RA was similar in patients with a homozygous mutant (53 $(12.3)$ years), heterozygous (45 (13.0) years), and homozygous wild-type genotype (49 (13.4) years).

\section{Discussion}

This study has demonstrated that there appears to be a modest association between 
susceptibility to AS and CYP2D6 genotype, and that this effect is greatest for the CYP2D6B allele. However, no association between RA and CYP2D6 genotype was detected. The number of patients studied was small and because the frequency of the poor metaboliser genotype in the control population is only $5 \%$, the statistical power is limited. We estimate that to achieve $60 \%$ statistical power with the sample size of the AS or RA group, the odds ratios would have to lie between 4 and 5. The allele frequencies for the CYP2D6B allele in the control group were similar to those reported for other British studies, ${ }^{12} 13$ suggesting that the control group used was appropriate. It can be assumed that, because recruitment was from special clinics, patients with severe disease have been investigated. This is reflected by the high proportion of patients with different extraskeletal features and the need for disease modifying antirheumatoid drugs. Differences from a control population should thus be detected easily.

The biological basis of the apparent association between CYP2D6 genotype and susceptibility to AS is unclear. Associations between CYP2D6 genotype and diseases such as lung cancer, bladder cancer, and Parkinson's disease have been demonstrated, ${ }^{4}$ but these associations are probably related to metabolism of environmental toxins by CYP2D6. However, the finding of a stronger association for the CYP2D6B alleles than for the other mutant alleles might be suggestive of linkage disequilibrium with another gene with a more direct role in the disease in the region of CYP2D6 on chromosome 22.

The finding of an apparent increase in the frequency of the poor metaboliser phenotype among AS patients suggests that the incidence of certain adverse drug reactions in individuals suffering from this disease may be greater than normal. We have previously demonstrated in a study of RA patients that the widely used analgesic dextropropoxyphene affects CYP2D6 phenotype. ${ }^{14}$ However, this drug is believed to be a CYP2D6 inhibitor rather than a substrate, therefore its use in poor metabolisers may not necessarily present problems. The other most commonly used CYP2D6 drug substrate likely to be used in the treatment of AS is codeine. Poor metabolisers are unable to activate this drug to morphine, and it has been demonstrated to be an inefficient analgesic among a group of poor metabolisers. ${ }^{15}$

Although requiring confirmation in a larger patient group, this study suggests that, in addition to playing a part in susceptibility to systemic lupus erythematosus, ${ }^{5}$ CYP2D6 genotype may also play a modest role as a susceptibility factor in AS.

We thank Mr Robert Addyman and Miss Susan Dimmock for technical support, Dr Christoph Minder for statistical advice
and Mrs Doris Messer for secretarial help. Dr Christine Beyeler and Mrs Doris Messer for secretarial help. Dr Christine Beyeler
acknowledges financial support from the Swiss National acknowledges financial support from the Swiss National
Foundation (1990) and the Arthritis and Rheumatism Council (1991). The Clinical Pharmacology Unit acknowledges financial support from Roche Products Limited, the Pharmacogenetics Unit from BAT Limited.

1 Gonzalez F J. Human cytochromes P450: problems and prospects. Trends Pharmacol Sci 1992; 13: 346-52.

2 Cholerton S, Daly A K, Idle J R. The role of individual human cytochromes $\mathbf{P 4 5 0}$ in drug metabolism and clinical response. Trends Pharmacol Sci 1992; 13: 434-8.

3 Daly A K, Armstrong M, Monkman S C, Idle M E, Idle J R. Genetic and metabolic criteria for the assignment of debrisoquine 4-hydroxylation (cytochrome P4502D6) phenotypes. Pharmacogenetics 1991; 1: 33-41.

4 Daly A K, Cholerton S, Armstrong M, Idle J R. Genotyping for polymorphisms in xenobiotic metabolism as a predictor of disease susceptibility. Environ Health Perspect 1994; 102: 55-61.

5 Baer A N, McAllister C B, Wilkinson G R, Woosley R L, Pincus $T$. Altered distribution of debrisoquine oxidation phenotypes in patients with systemic lupus erythematosus. Arthritis Rheum 1986; 29: 843-9.

6 May D G, Black C M, Olsen N J, et al. Scleroderma is associated with differences in individual routes of drug metabolism: a study with dapsone, debrisoquin and mephenytoin. Clin Pharmacol Ther 1990; 48: 286-95.

7 Khan M A, Kellner $H$. Immunogenetics of spondyloarthropathies. Rheum Dis Clin North Am 1992; 18 837-64.

8 Nepom G T, Nepom B S. Prediction of susceptibility to rheumatoid arthritis by human leukozyte antigen genotyping. Rheum Dis Clin North Am 1992; 18: 785-92.

9 van der Linden S, Valkenburg H A, Cats A. Evaluation of diagnostic criteria for ankylosing spondylitis. A proposal for modification of the New York criteria. Arthritis Rheum 1984; 27: 361-8.

10 Arnett F C, Edworthy S M, Block D H, et al. The American Rheumatism Association 1987 revised criteria for the classification of rheumatoid arthritis. Arthritis Rheum 1988; 31: 315-24.

11 Gardner M J, Altman D G. Statistics with Confidence. London: BMJ, 1989.

12 Wolf C R, Smith C A D, Gough A C, et al. Relationship between the debrisoquine hydroxylase polymorphism and cancer susceptibility. Carcinogenesis 1992; 13: 1035-8.

13 Smith C A D, Gough A C, Leigh P N, et al. Debrisoquine hydroxylase gene polymorphism and susceptibility to hydroxylase gene polymorphism and suscep

14 Beyeler C, Daly A K, Armstrong M, Astbury C, Bird H A, Idle J R. Phenotype/genotype relationships for the cytochrome P450 enzyme CYP2D6 in rheumatoid arthritis: Influence of drug therapy and disease activity. f Rheumatol 1994; 21: 1034-9.

15 Sindrup S H, Brosen K, Bjerring K, et al. Codeine increases pain thresholds to copper vapor laser stimuli in extensive but not poor metabolizers of sparteine. Clin Pharmacol Ther 1991; 49: 686-93. 